\title{
Spatial Trend Analysis of Temperature and Rainfall and Their Perceived Impacts on Ecosystem Services in Mau Forest, Kenya
}

\author{
Alice Jebiwott ${ }^{1 *}$, George Morara Ogendi ${ }^{2,3}$, Busuyi Olasina Agbeja ${ }^{4}$, Abiodun Akintunde $\mathrm{Alo}^{4}$, Geoffry Mukonambi \\ Maina $^{2}$ \\ ${ }^{1}$ Department of Environmental Management, Pan African University Life and Earth Sciences Institute, University of Ibadan, \\ Ibadan, Nigeria \\ ${ }^{2}$ Department of Environmental Science, Egerton University, P.O Box 536-20115, Egerton, Kenya \\ ${ }^{3}$ Dryland Research Training and Ecotourism Centre, Chemeron, P.O Box 536-20115, Egerton, Kenya \\ ${ }^{4}$ Department of Forest Resource Management, University of Ibadan, Private Bag, Ibadan, Nigeria
}

Corresponding Author Email: aliciaphil.chebby@gmail.com

https://doi.org/10.18280/ijsdp.160504

Received: 11 May 2021

Accepted: 29 July 2021

\section{Keywords:}

Mau Forest, rainfall, temperature, climate

change, Mann Kendell, trend analysis

\begin{abstract}
The Mau Forest Complex is an important ecosystem in Kenya providing many ecosystem services to the local communities. However, its degradation has rendered its ability to deliver its ecosystem services such as climate regulation ineffective. This study's objective was to assess the local climate trend in terms of rainfall and temperature and their perceived impacts on ecosystem services in Mau Forest, from 1984 to 2020. We obtained gridded meteorological data for the study area from the Kenya Meteorological Department and analyzed it using Mann Kendell's test to identify significant trends in temperature and rainfall. Focus Group Discussions were also carried out to establish the people's perceptions of local climate change and its impacts on ecosystem services. The results of the study indicate no significant trend, $\mathrm{p}>0.05$, in annual rainfall over time. On the other hand, the results show a significant trend, $\mathrm{p}=3.696 \mathrm{e}-06$, in average annual temperature with approximately $2^{\circ} \mathrm{C}$ increase from 1984 to 2020. The local climate change has seen a decline in ecosystem services, mainly water levels and agricultural produce. To cope with and mitigate the effects of climate change, there is need to emphasize establishment of agroforestry woodlots and practice of climate-smart agriculture among the forest adjacent communities.
\end{abstract}

\section{INTRODUCTION}

The climate change trend scenario presents a significant challenge, especially to the scientific community, in managing natural resources including forests [1]. Empirical evaluation of climate change trends and future projections of climate state globally indicate wide variations. According to the IPCC report by Bernstein et al. [2], the global surface temperatures are expected to increase by $1.5^{\circ} \mathrm{C}$ and $5.8^{\circ} \mathrm{C}$ by 2100 . Further projections indicate a global warming rate of $0.2^{\circ} \mathrm{C}$ and 0.5 per decade. In Africa, climate change trend implications have been closely monitored by IPCC. For instance, in East Africa, precipitation is expected to increase. Extreme weather events are expected to increase from $5 \%$ to about $20 \%$. These climatic changes have significant impacts on forests which in turn affect their ecosystem services. These services are essential in stabilizing global climates and natural cycles while providing goods that improve livelihoods. However, the forest function in the ecology in delivering ecosystem services is compromised by various factors, including climate change [3].

Recent studies single out climate change as a significant contributor to forest ecosystems' damage, affecting their ability to provide essential ecosystem services. The impacts of climate change on forests primarily manifest in structural modification and functionality variation of forest vegetation. These changes have mainly been through periodic disturbances and alterations that induce the forest ecosystem's transformation [4]. A study by Rowland and others [5], established that forest disturbances result from the changing effect of abiotic factors such as fire, rainfall, drought, and wind A study by Erfanian et al. [6], emphasized that due to drought effects triggered by climate change trends, only trees that adapted to the changing climatic conditions can thrive. This generally has affected forest ecosystems' functionality worldwide. Research on the Canadian Boreal Forest pointed out that due to the impacts of global warming and weatherrelated events such as storms, certain species have been damaged [7]. The damage caused limits the ability of the boreal forest ecosystem to provide various services. These services include provision of livelihood options such as employment, recreational use, global carbon cycle, and regulating global climate [8].

Another study carried out in Amazon presented evidence that suggests a great variation of the composition of Amazon forests due to climate change trends over the last 30 years [9]. This result can be projected to most tropical forests including those in Kenya given their similarity in geographic location. Elsewhere in Europe, it was estimated that storms caused 53\% of 35 million $\mathrm{m} 3$ wood damage. This damage was documented for the temperate oceanic, boreal, temperate continental, mountainous, and Mediterranean forests in Europe [10]. Moreover, a study by Staudinger and others [11], found out 
that timber production has been unevenly affected by climate change in the U.S. hence affecting local consumption. In California, Shaw et al. [12], observed that climate change had affected forests' capacity to regulate temperatures in the suburban and urban areas. This has yielded extreme conditions of high and low temperatures.

Other documented studies link climate change to various disturbances, such as the outbreak of pests, the emergence of invasive species, the spread of wildfires and storms that alter forest components [13]. A study in Colorado estimated that pine beetles had damaged more than 650,000 acres of forest, while in Western Canada and Alaska, spruce beetles had destroyed more than 3.7 acres of forests [14].

Over the years, the impacts of climate change have affected Africa primarily due to the vulnerability contexts such as overdependence on natural resources [15]. A study by Chidumayo and others [16], on the effects of climate change on African forests highlights little knowledge concerning African forests' capacity to adapt to climate change. Since different forest vegetation types respond distinctively to climatological conditions, there is a need to conduct further investigations on different species' responses to the changing conditions. However, research carried out on Kilimanjaro Forests in Tanzania, East Africa, established that the forest had undergone drastic climatic changes over the last 120 years, with rainfall amounts decreasing by an estimated 600$1200 \mathrm{~mm}$, and temperatures increasing [17, 18]. These changing climatic conditions have caused fires and the melting of glaciers hence affecting Kilimanjaro Forest ecosystems.

In Kenya, forests play a significant role in improving the economy. They contribute to environmental, socio-cultural, and economic spheres of life through their various ecosystem services. Mau forest is one of such ecosystems and the largest of the country's five central water towers. It plays an invaluable role in providing the forest-dwelling and adjacent communities with various ecosystem services such as herbal medicine, construction material, firewood, fodder, honey, and wild fruits, among other provisioning services. It also acts as a carbon sink, conserves soil and water, recharges groundwater, regulates the flow of water in rivers and streams, mitigates floods and soil erosion, and above all, is a habitat for biodiversity [19]. These services support a wide array of sectors such as agriculture and tourism. Recent research contends that climate change, precisely erratic water supply, is the primary cause of the decline of mangrove forest cover of Coastal areas in Mombasa [20]. The decrease of the Mau Forest Complex in Kenya is majorly attributed to anthropogenic activities and climate variation. The irregular rainfall patterns are the key driver to the decline of the forest cover [21]. Researchers have paid little attention on the trends of local climatic changes in Mau Forest and how these changes affect the ecosystem services thus the basis for this research. The objective of this study is to assess the trends in temperature and rainfall and their perceived impacts on ecosystem services in the Mau Forest over the period 1984 and 2020 .

\section{MATERIALS AND METHODS}

\subsection{Study area}

The Mau Forest Complex (Figure 1) is the largest remaining montane indigenous forest in East Africa, covering more than
400,000 ha. It lies between $0.6114^{\circ} \mathrm{S}$ and $35.7407^{\circ} \mathrm{E}$ in the Rift Valley Province of Kenya. As the main catchment area in Kenya, the forest feeds Lakes Victoria, Nakuru, Natron, and the White Nile. It also has numerous streams and rivers originating from it, including the rivers Njoro, Makalia, Enderit, Sondu, Mara River systems, and the Southern Ewaso Ngiro system. The rivers support agriculture, hydropower, urban water supply, tourism, and wildlife habitat throughout the country. Besides, the forest supports the ecosystems and livelihoods in the Serengeti and Maasai Mara National Parks.

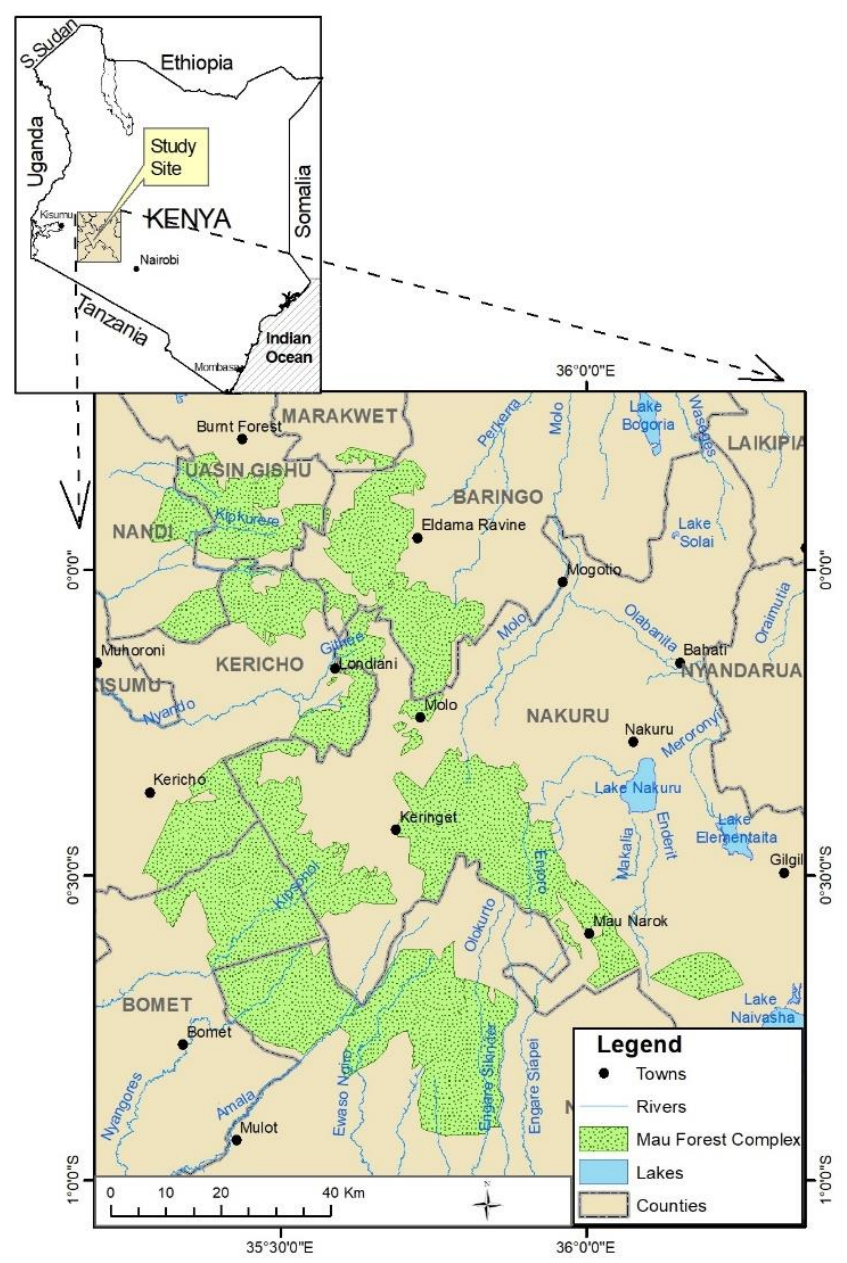

Figure 1. Map of Mau Forest

The forest is also home to rare indigenous trees such as Juniperus procera, Olea africana, Bambusa vulgaris, Polyscias kikuyuensis, Tabernaemontana stapfiana, Syzygium guineense, Neoboutonia macrocalyx, Olea capensis, Prunus africana, Albizia gummifera, Podocarpus latifolius, Dombeya goetzenii, Grevillea robusta and Croton megalocarpus among many other trees. It also has exotic trees such as Cupressus lusitanica, Pinus patula and Eucalyptus grandis regularly planted by the Kenya Forest Service, mainly for commercial purposes.

The forest's original inhabitants, the Ogiek, who have lived there for hundreds of years, continue to call the forest their home. They are predominantly hunters and gatherers hence make their livelihood from the forest.

\subsection{Data sources}

For the trend in rainfall and temperature, Gridded 
temperature and precipitation datasets for the years 1984 to 2020 were obtained from the Kenya Meteorological Department (KMD). The geometrically and radiometrically corrected data were based on daily and monthly timescales and had high spatial and temporal resolutions of 0.50 by 0.50 . To augment the meteorological data, and to assess the perceptions of the community on the impacts of local climate change on the ecosystem services, Focus Group Discussions were conducted.

\subsection{Data analysis}

Analysis of climate trends by modelling time series climatic data, in this study's case temperature and precipitation, is among the most common tools used to predict short-term or long-term climate changes [22]. Most climate science-related studies have been conducted to estimate global warming's impact on climate variation using statistical techniques to assign numbers to the warming. Non-parametric descriptions, accelerated increases, change points, linear curves and many other methods are well developed to handle statistical trend estimation. Climate data have peculiar aspects such as autocorrelation and non-Gaussian shape distribution which are taken into consideration by robust computational-intensive simulation algorithms.

The Mann-Kendall (MK) test, which is a commonly used non-parametric statistical method [23], was applied in this study to identify significant trends in rainfall and temperature in the Mau Forest Complex for the period 1984 to 2020. Geometrically and radiometrically corrected meteorological data for the study area from the KMD were applied into Equations 1 to 4 to establish the climate trends.

Given a time series $x_{1}, x_{2} \ldots x_{n}$, the MK test applies the following statistic:

$$
S=\sum_{i=1}^{n-1} \sum_{j=k+1}^{n} \operatorname{sign}\left(x_{j}-x_{i}\right)
$$

Note that later observations in a time series dataset are likely to be greater than earlier ones if $S>0$ and vice versa when $S<0$.

A variance of $\mathrm{S}$ is represented in Eq. (2) as:

$$
\text { var }=1 / 18\left[n(n-1)(2 n+5)-\sum_{t} f_{t}\left(f_{t}-1\right)\left(2 f_{t}+5\right)\right]
$$

where, $t$ fluctuates over a set of fixed ranks and $f_{t}$ is the frequency of rank $t$ appearance.

The MK-test applies the statistic in Eq. (3) as:

$$
z=\left\{\begin{aligned}
(S-1) / s e, & S>0 \\
0, & S=0 \\
(S+1) / s e, & S<0
\end{aligned}\right.
$$

where, se is the variance square root.

The test statistic $z$ in Eq. (3) represents a measure of the trend's significance, mainly to test the null hypothesis. If the significance $z<0.05$, then a trend exists, whereas $z>0.05$ depicts no trend.

In addition to the MK test, another statistic, Kendall's tau, is obtained to measure correlation and the relationship between the two variables. Autocorrelation usually implies increased chances of significant trend detection, although they might be absent and vice versa. Hamed and Ramachandra Rao [24], proposed a modified MK test that takes into consideration autocorrelation among data ranks after eliminating the supposed trends. This is represented in Eq. (4) as:

$$
\operatorname{Var}=1 / 18[N(N-1)(2 N+5)]^{N} / N S^{*}
$$

where;

$$
\begin{aligned}
N / N S^{*}=1+ & \frac{2}{N(N-1)(N-2)} \sum_{i=1}^{p}(N-i)(N-i \\
& -1)(N-i-2) p_{s}(i)
\end{aligned}
$$

$N=$ total observations number in the sample,

$N S^{*}=$ effective number of observations to check for autocorrelation in the dataset,

$p_{s}(i)=$ autocorrelation among ranks of observations for lag $I$, and,

$p=$ maximum time lag under consideration.

The Kendall's tau values range between $+/-1$, where a positive value indicates that the two variables' rank increase collectively. In contrast, a negative value suggests that one variable's rank increases while the other decreases. Figure 2 illustrates the climate trend analysis process.

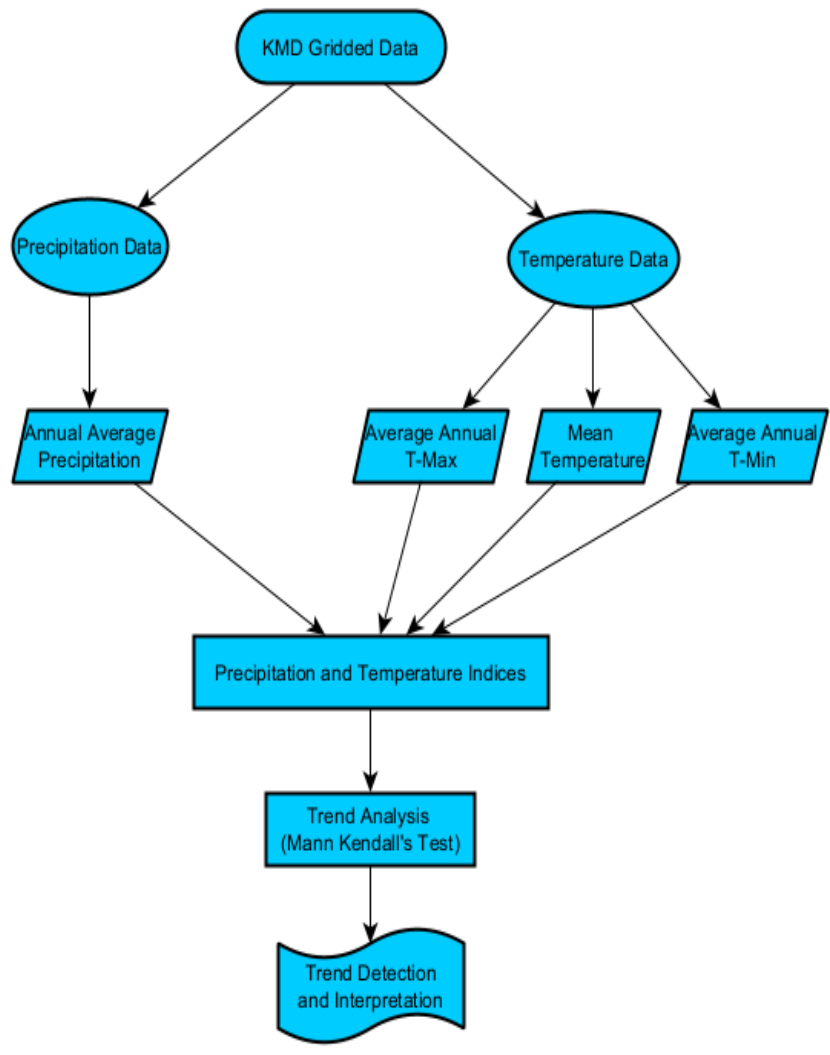

Figure 2. Trend analysis flowchart

\section{RESULTS AND DISCUSSION}

\subsection{Climate trend in Mau complex}

Climate-related research and adaptation focus is centered on climate-driven change detection in connected human-natural systems. In regions where rain-fed agriculture is prominent, probing spatio-temporal changes of meteorological variables is necessary for assessment of climate change. Therefore, to adapt to these changes, its impact on forestry, agriculture and water resources needs to be well understood. 
Trend analysis was employed to detect the changes in temperature and rainfall in the Mau Forest complex. Gridded monthly Climate Hazards Group Infrared Precipitation with Station (CHIRPS) data with $0.5^{\circ} \mathrm{X} 0.5^{\circ}$ resolution, which was established in cooperation with Earth Resource Observation and Science (EROS) Center, were probed for trend identification using the Mann Kendell's (MK) test at 5\% significance $(\mathrm{p}<0.05)$ level.

\subsection{Rainfall}

Monthly and yearly averages of gridded rainfall data were analyzed across the study period from 1984 to 2020 as shown in Figure 3. The year 2013 recorded the highest ever annual rainfall with a total of approximately $1622 \mathrm{~mm}$. The years 1984 and 2009 recorded the lowest with around $850 \mathrm{~mm}$ and $880 \mathrm{~mm}$ respectively. The study established a slight trend of increasing rainfall across the study period despite decreasing forest cover, but the adjusted R-Square value of 0.0305 implies little significance of increasing rainfall with time.

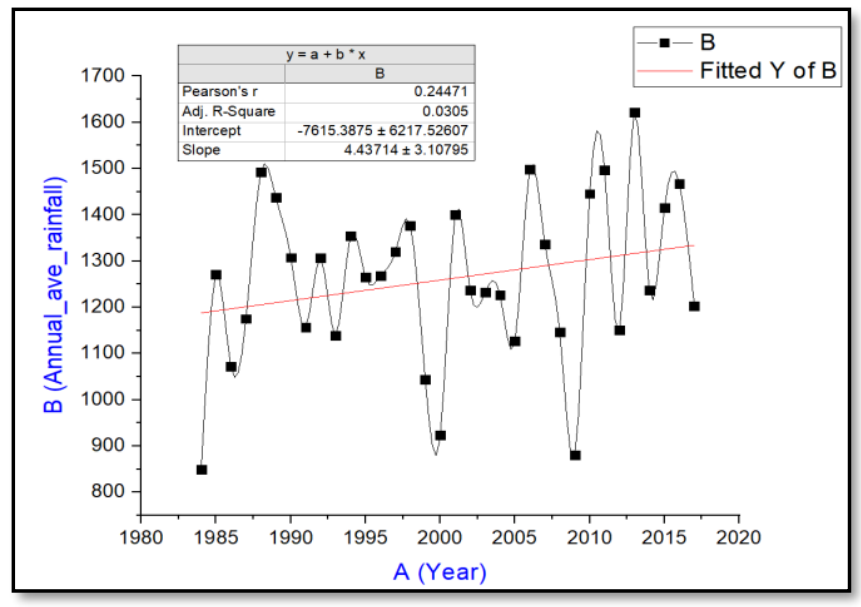

Figure 3. Annual average precipitation (mm)

To support this trend, the MK test returned a low tau value of 0.134 which means that as time lapsed, the increase and decrease of annual precipitation over the years could not depict a significant trend despite the trend line trying to imply an increasing trend as shown in Figure 3. This is further supported by a high 2 -sided p-value of 0.27264 which shows that there is no significant trend in annual precipitation over time, with the case being random increasing and decreasing rainfall from the year 1984 onwards.

A similar study conducted by Muhati and others [25], in Marsabit Forest Reserve, also employed MK-test to asses existing trends in rainfall, and it returned no significant trend where $p>0.05$. Their findings further corroborated the random changes in rainfall encountered in the study area. Their findings indicated that at least ten years between 1973 and 2009 would be grouped as severely or moderately dry.

This means that the precipitation uncertainty was felt across the country and the region as highlighted in a study by Gebrechorkos et al. [26]. There was a non-significant change across the region from the long-term seasonal rainfall trend analysis. However, during the long rains of March, April and May, there was a non-significant increasing trend as well as during the short rains of October, November and December.

A study conducted by Rao and others [27], in Eastern Kenya, the farthest region east of Mau complex, examined the perceptions of farmers on long-term and short-term climate variations and compared the results to analyzed survey data from Kenya Meteorological Department (KMD). Despite the farmers having knowledge and consistent discernment of variations in rainfall, their views were more subjective to factors that affect crop production. The results from the analysis of meteorological data in the region showed very high variability in recorded annual rainfall amounts. They were characterized by short cycles of approximately five years of swings of La Nina (low rainfall spells) and El Nino (very high rainfall). Just like this study's findings on rainfall trends, there was no distinguishable decreasing or increasing trend in seasonal or annual rainfall.

The repercussions of global changes in climate, specifically precipitation, as a result of forest cover loss are threats to food security in rain-dependent agricultural regions. Application of traditional knowledge on planting seasons guided by predictable raining months has now become unreliable in many African countries [28]. The researcher further linked high variations in annual rainfall to long term decline of global forest cover as compared to the period before 1970s. After 1970s, global forest cover declined at alarming rates and two decades later, in the early 1990s, significant impacts were felt on the trends of rainfall which became more unpredictable onwards [28].

A study by Guan an others [29], revealed reduced crop yields in the years where rainfall did not fall during the expected planting seasons. In comparison to focus group discussion results in this study, one of the biggest drivers that pushed people to convert forest area to agricultural farms was due to unpredictable rainfall patterns. To increase returns, most residents around the forest resorted to clearing forest land to increase agricultural land area and consequently yields because there was reduced yields from small-sized farms.

\subsection{Temperature}

Annual averages of minimum and maximum temperatures were analyzed from the year 1984 to 2020 to assess the trend in temperature change as shown in Figures 4, 5, and 6.

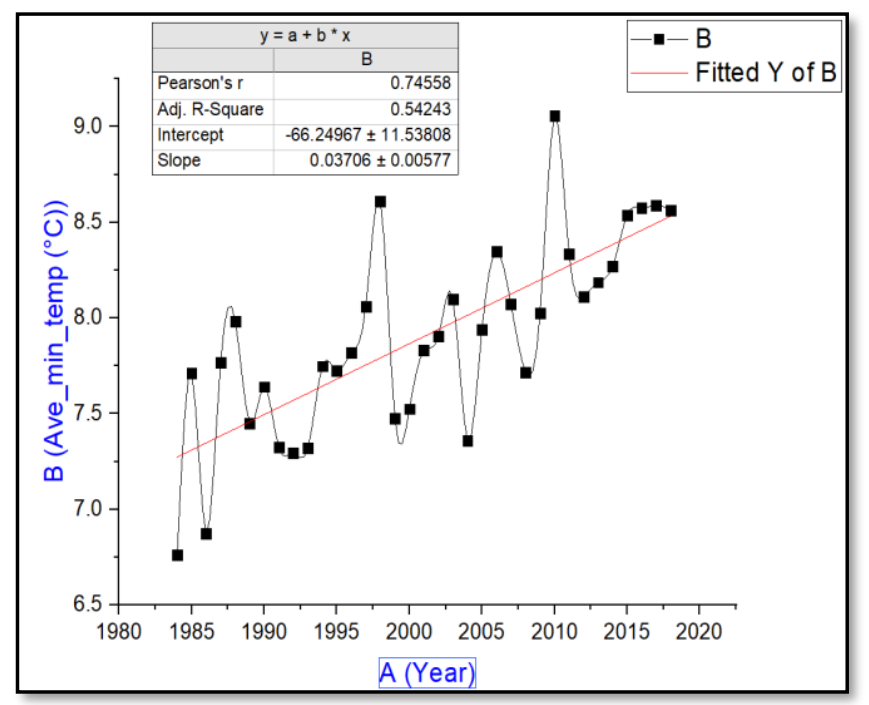

Figure 4. Average annual minimum temperature

There was a steady increase in temperature from the base year 1984 to 2020 by approximately $2^{\circ} \mathrm{C}$. Wolff and others, [30] in a study, linked forest cover loss to warmer and drier local temperatures which can be related to this study. The 
coldest year was 1984 with $13.8^{\circ} \mathrm{C}$ while the hottest year was 2017 with approximately $15.5^{\circ} \mathrm{C}$.

From the MK test, a positive tau value was achieved at 0.558 which implies that as the years went by from 1984, there was subsequent increase in annual average temperature. From Eq. (3), $z$ which is a representation of the significance returned a 2 -sided $p$ value of $3.696^{\mathrm{e}-06}$. This value is below the threshold value $z<0.005$ hence we can conclude that there exists a trend in average annual temperature, which in this study's case was increasing over time.

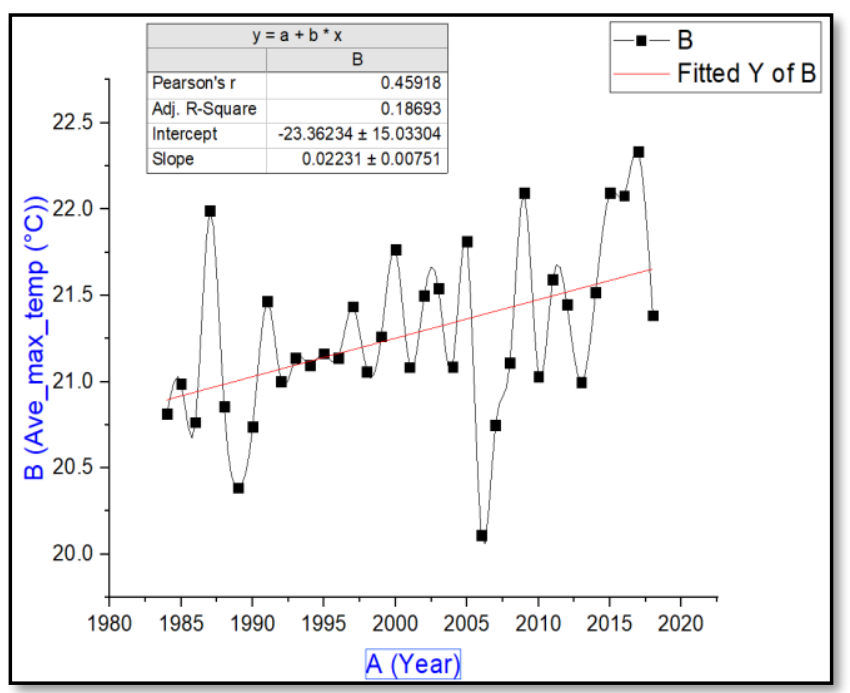

Figure 5. Average annual maximum temperature

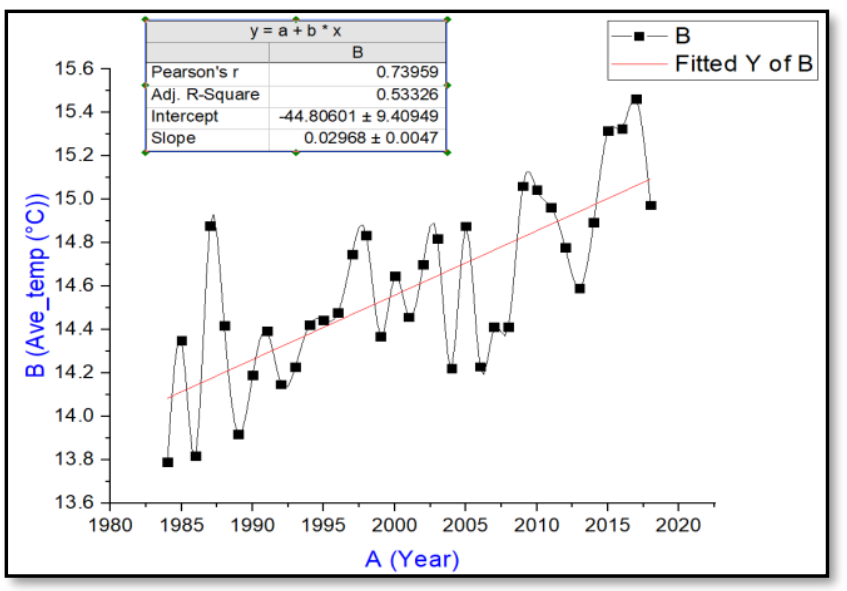

Figure 6. Average annual temperature

A comparison to a study by Muhati and others [25], on temperature trends in Marsabit Forest Reserve also corresponded with this study's findings. There was a significant increasing trend in temperature witnessed according to the MK-test where $p<0.05$. This means that annual temperature increase witnessed in Mau complex was not necessarily impacted by local forest cover changes, but as a result of national or regional temperature increase.

A similar study on a regional scale covering Kenya, Tanzania and Ethiopia by Gebrechorkos et al. [26], just like this study, revealed increasing trends in minimum and maximum temperature of up to $+1.2^{\circ} \mathrm{C}$ and $+1{ }^{\circ} \mathrm{C}$ respectively. These changes were rampant in the months of March, April and May, which coincidentally experienced non-significant increase in precipitation trends. Previous studies based on coarse resolution precipitation data concluded no significant trends in rainfall on annual time scales in East Africa.

\subsection{Perceptions on Impacts of Climate Change on Ecosystem Services}

According to Rustad et al. [31], and Grimm et al. [32], changes in climate can alter the structure and functions of the forest and in effect render it inefficient in providing the ecosystem services. The ecosystem services that are mostly threatened by climate change are the provisioning and the regulating services. The communities that live in and around the Mau Forest are highly dependent on the ecosystem for their livelihoods. The FGD participants noted that they have witnessed increasing temperatures and fluctuating rainfall patterns. This supports the results from the spatial analysis and is a confirmation that there has indeed been changes in the local climate. The narrations of the participants are also consistent with the findings of Chaudhry [33], who noted that the temperatures in the Mau forest have been increasing and the rainfall patterns have become erratic. Chaudry further notes that, with the changing local climate, forest resources have become scarce and this has greatly impacted on the livelihoods of the adjacent communities who are highly dependent on the ecosystem. The FGD participants further narrated that the changes have affected their agricultural production which have since reduced in yield. They noted that the planting and harvesting seasons have been altered since the onset of the long rains, which usually would be from March to May, have changed and is now unpredictable. This has led to varying planting seasons since they need to await the onset of the rains before they can plant.

From the discussion, it is evident that the ecosystems regulation services have been affected hence the effect on the provision of water. This is in line with Sintayehu [34], who documented that there is a rise in temperature and variability in precipitation in the African continent. He further stated that communities in Africa depend of rainfed agriculture and owing to the changes and variability in climate, crops that take a long period to mature have been affected by the declining rainfall during the March-May wet season. This has in turn resulted in low yields thereby affecting the availability of food supply.

Moreover, the FGD respondents revealed that there has been reduced river flow owing to the decline in rainfall. Some of the rivers have become seasonal leading to the locals travelling for long distances to fetch water. Another change that the participants linked to climate change is the reduced soil fertility. They recounted that since the crop yield have reduced, farmers would over cultivate and plant crop after crop in order to increase the chances of increasing the yield. This would then lead to overcultivation and reduction in the fertility of the soil. According to Arora [35], overcultivation leads to land degradation which in turn influence the micro-climate and consequently desertification. Other ecosystem services that were reported by the FGD respondents as having declined are honey, mushrooms, medicinal plants and decline in fauna.

\subsection{Implications on policy making}

Forest managers and policy makers should promote and popularize non-timber forest products so that the communities embrace such sustainable alternative livelihoods in such forest ecosystems. This could help diversify livelihoods therefore coping with changes in local climate. 
Forest conservation measures and strategies such as establishment of agroforestry woodlots and practicing of climate-smart agriculture, including conservation agriculture, among communities living around the forest should be emphasized. This will help them cope with and be able to mitigate the impacts of local climate change.

The community members should be involved in decision making regarding the management of the forest. This way, they will actively and sustainably utilize and manage the forest resources and thereby an improvement in the ecosystem services.

Conservation projects such as the REDD+ should be implemented in order to increase the provision of ecosystem services which in turn will help the local communities in adapting to climate change.

\section{CONCLUSIONS}

From this study, we can conclude that there has been an increasing trend in temperature and fluctuating rainfall patterns, a manifestation that the local climate has changed. The study established random increasing and decreasing rainfall from the year 1984 onwards while temperature has increased since 1984 to 2020 by approximately $2^{\circ} \mathrm{C}$. The effects of climate change have been felt by the community owing to the negative impacts that the changes have had on the ecosystem. The ecosystem's ability to provide some of the ecosystem services, more especially the regulating and the provisioning services has been decreased. Some of the effects felt by the community as a result of impacts of climate change on the ecosystem services include decline in crop yields, decrease in water flow in streams, unpredictable planting and growing seasons and reduced soil fertility. Therefore, there is need for the forest managers to develop specific policies and strategies, with full involvement of the community members, pertaining to establishment of woodlots, awareness campaigns and incorporation of climate smart agriculture interventions in addressing climate change issues facing the local communities.

\section{ACKNOWLEDGMENT}

This work was supported by the Pan African University Life and Earth Sciences Institute (PAULESI) as part of a Doctorate Degree Programmme in Environmental Management, and the African Forest Forum (AFF).

\section{REFERENCES}

[1] Cramer, W., Guiot, J., Fader, M., Garrabou, J., Gattuso, J.P., Iglesias, A., Lange, M.A., Lionello, P., Llasat, M.C. Paz, S., Peñuelas, J., Snoussi, M., Toreti, A., Tsimplis, M.N., Xoplaki, E. (2018). Climate change and interconnected risks to sustainable development in the Mediterranean. In Nature Climate Change, 8(11): 972980. https://doi.org/10.1038/s41558-018-0299-2

[2] Bernstein, L., Bosch, P., Canziani, O., Chen, Z., Christ, R., Davidson, O., Hare, W., Huq, S., Karoly, D., Kattsov, V., Kundzewicz, Z., Liu, J., Lohmann, U., Manning, M., Matsuno, T., Menne, B., Metz, B., Mirza, M., Nicholls, N., ... Madan, P. (2007). IPCC Climate Change 2007: Synthesis Report

(Vol.

104). https://www.ipcc.ch/site/assets/uploads/2018/02/ar4_syr _full_report.pdf.

[3] Seidl, R., Honkaniemi, J., Aakala, T., et al. (2020). Globally consistent climate sensitivity of natural disturbances across boreal and temperate forest ecosystems. Ecography, 43(7): 967-978. https://doi.org/10.1111/ecog.04995

[4] Resco De Dios, V., Fischer, C., Colinas, C. (2007). Climate change effects on Mediterranean forests and preventive measures. In New Forests, 33(1): 29-40. https://doi.org/10.1007/s11056-006-9011-x

[5] Rowland, L., Da Costa, A.C.L., Galbraith, D.R., Oliveira, R.S., Binks, O.J., Oliveira, A.A.R., Pullen, A.M., Doughty, C.E., Metcalfe, D.B., Vasconcelos, S.S., Ferreira, L.V., Malhi, Y., Grace, J., Mencuccini, M., Meir, P. (2015). Death from drought in tropical forests is triggered by hydraulics not carbon starvation. Nature, 528(7580):

119-122. https://doi.org/10.1038/nature15539

[6] Erfanian, A., Wang, G., Fomenko, L. (2017). Unprecedented drought over tropical South America in 2016: Significantly under-predicted by tropical SST. Scientific Reports, 7(1). https://doi.org/10.1038/s41598017-05373-2

[7] Brandt, J.P., Flannigan, M.D., Maynard, D.G., Thompson, I.D., Volney, W.J.A. (2013). An introduction to Canada's boreal zone: Ecosystem processes, health, sustainability, and environmental issues1. Environmental Reviews, 21(4): 207-226. https://doi.org/10.1139/er-2013-0040

[8] Lemprière, T.C., Kurz, W.A., Hogg, E.H., Schmoll, C., Rampley, G.J., Yemshanov, D., McKenney, D.W., Gilsenan, R., Beatch, A., Blain, D., Bhatti, J.S., Krcmar, E. (2013). Canadian boreal forests and climate change mitigation1. In Environmental Reviews, 21(4): 293-321. https://doi.org/10.1139/er-2013-0039

[9] Esquivel-Muelbert, A., Baker, T.R., Dexter, K.G., et al. (2019). Compositional response of Amazon forests to climate change. Global Change Biology, 25(1): 39-56. https://doi.org/10.1111/gcb.14413

[10] Schelhaas, M.J., Nabuurs, G.J., Schuck, A. (2003). Natural disturbances in the European forests in the 19th and 20th centuries. Global Change Biology, 9(11): 16201633. https://doi.org/10.1046/j.13652486.2003.00684.x

[11] Staudinger, M.D., Grimm, N.B., Staudt, A., Carter, S.L., Stuart, F., Iii, C., Kareiva, P., Ruckelshaus, M., Stein, B.A. (2013). Impacts of climate change on biodiversity, ecosystems, and ecosystem services: Technical input to the 2013 national climate assessment. Cooperative Report to the 2013 National Climate Assessment (Vol. 296). http://assessment.globalchange.gov.

[12] Shaw, M.R., Pendleton, L., Cameron, D.R., Morris, B., Bachelet, D., Klausmeyer, K., MacKenzie, J., Conklin, D.R., Bratman, G.N., Lenihan, J., Haunreiter, E., Daly, C., Roehrdanz, P.R. (2011). The impact of climate change on California's ecosystem services. Climatic Change, 109(SUPPL. 1): 465-484. https://doi.org/10.1007/s10584-011-0313-4

[13] Dale, V.H., Joyce, L.A., McNulty, S., Neilson, R.P., Ayres, M.P., Flannigan, M.D., Hanson, P.J., Irland, L.C., Lugo, A.E., Peterson, C.J., Simberloff, D., Swanson, F.J., Stocks, B.J., Wotton, B.M. (2001). Climate Change and Forest Disturbances Climate change can affect forests by altering the frequency, intensity, duration, and timing of 
fire, drought, introduced species, insect and pathogen outbreaks, hurricanes, windstorms, ice storms, or landslides. BioScience, 51(9): 723-734. https://doi.org/10.1641/0006-

3568(2001)051[0723:CCAFD]2.0.CO;2

[14] Backlund, P., Janetos, A., Schimel, D. (2008). Synthesis and Assessment Product 4.3 The Effects of Climate Change on Agriculture, Land Resources, Water Resources, and Biodiversity in the United States. http://www.climatescience.gov.

[15] Kurukulasuriya, P., Mendelsohn, R. (2007). Crop selection: Adapting to climate change in Africa. The World Bank. https://doi.org/10.1596/1813-9450-4307

[16] Chidumayo, E., Okali, D., Kowero, G., Larwanou Editors, M. (2011). Climate change and African forest and wildlife resources African forest forum-a platform for stakeholders in African Forestry. www.afforum.org.

[17] Hemp, A. (2005). Climate change-driven forest fires marginalize the impact of ice cap wasting on Kilimanjaro. Global Change Biology, 11(7): 1013-1023. https://doi.org/10.1111/j.1365-2486.2005.00968.x

[18] Hemp, A. (2009). Climate change and its impact on the forests of Kilimanjaro. African Journal of Ecology, 47(SUPPL. 1): 3-10. https://doi.org/10.1111/j.13652028.2008.01043.x

[19] Kipkoech, A., Mogaka, H., Cheboiywo, J., Kimaro, D. (2011). The Total Economic Value of Maasai Mau, Trans Mara and Eastern Mau Forest Blocks, of the Mau Forest, Kenya. www.lvbcom.org.

[20] Huxham, M., Emerton, L., Kairo, J., Munyi, F., Abdirizak, H., Muriuki, T., Nunan, F., Briers, R.A. (2015). Applying Climate Compatible Development and economic valuation to coastal management: A case study of Kenya's mangrove forests. Journal of Environmental Management 157:

$168-181$. https://doi.org/10.1016/j.jenvman.2015.04.018

[21] Kinyanjui, M.J. (2011). NDVI-based vegetation monitoring in Mau forest complex, Kenya. African Journal of Ecology, 49(2): 165-174. https://doi.org/10.1111/j.1365-2028.2010.01251.x

[22] Mahmood, R., Jia, S., Zhu, W. (2019). Analysis of climate variability, trends, and prediction in the most active parts of the Lake Chad basin, Africa. Scientific Reports, 9(1): 1-18. https://doi.org/10.1038/s41598-01942811-9

[23] Gocic, M., Trajkovic, S. (2013). Analysis of changes in meteorological variables using Mann-Kendall and Sen's slope estimator statistical tests in Serbia. Global and Planetary Change, 100: 172-182. https://doi.org/10.1016/j.gloplacha.2012.10.014

[24] Hamed, K.H., Ramachandra Rao, A. (1998). A modified Mann-Kendall trend test for autocorrelated data. Journal of Hydrology. https://doi.org/10.1016/S00221694(97)00125-X
[25] Muhati, G.L., Olago, D., Olaka, L. (2018). Past and projected rainfall and temperature trends in a sub-humid Montane Forest in Northern Kenya based on the CMIP5 model ensemble. Global Ecology and Conservation, 16: e00469. https://doi.org/10.1016/j.gecco.2018.e00469

[26] Gebrechorkos, S.H., Hülsmann, S., Bernhofer, C. (2019). Long-term trends in rainfall and temperature using highresolution climate datasets in East Africa. Scientific Reports, 9(1): 1-9. https://doi.org/10.1038/s41598-01947933-8

[27] Rao, K.P.C., Ndegwa, W.G., Kizito, K., Oyoo, A. (2011) Climate variability and change: Farmer perceptions and understanding of intra-seasonal variability in rainfall and associated risk in semi-arid Kenya. In Experimental Agriculture, 47(2): 267-291. https://doi.org/10.1017/S0014479710000918

[28] Makurira, H. (2010). Rainfed agriculture in Sub-Saharan Africa. In Water Productivity in Rainfed Agriculture. https://doi.org/10.1201/b10823-3

[29] Guan, K., Sultan, B., Biasutti, M., Baron, C., Lobell, D.B (2015). What aspects of future rainfall changes matter for crop yields in West Africa? Geophysical Research Letters, $\quad$ 42(19): 8001-8010. https://doi.org/10.1002/2015GL063877

[30] Wolff, N.H., Masuda, Y.J., Meijaard, E., Wells, J.A., Game, E.T. (2018). Impacts of tropical deforestation on local temperature and human well-being perceptions. Global Environmental Change, 52: 181-189. https://doi.org/10.1016/j.gloenvcha.2018.07.004

[31] Rustad, L., Campbell, J., Dukes, J.S., Huntington, T., Lambert, K.F., Mohan, J., Rodenhouse, N. (2012). Changing Climate, Changing Forests: The Impacts of Climate Change on Forests of the Northeastern United States and Eastern Canada. http://www.nrs.fs.fed.us/.

[32] Grimm, N.B., Chapin, F.S., Bierwagen, B., Gonzalez, P., Groffman, P.M., Luo, Y., Melton, F., Nadelhoffer, K., Pairis, A., Raymond, P.A., Schimel, J., Williamson, C.E. (2013). The impacts of climate change on ecosystem structure and function. Frontiers in Ecology and the Environment, $11(9)$ : 474-482. https://doi.org/10.1890/120282

[33] Chaudhry, S. (2015). The impact of climate change on human security: The case of the MAU Forest Complex. Development (Basingstoke), 58(2-3): 390-398. https://doi.org/10.1057/s41301-016-0022-4

[34] Sintayehu, D.W. (2018). Impact of climate change on biodiversity and associated key ecosystem services in Africa: A systematic review. In Ecosystem Health and Sustainability, 4(9): 225-239. https://doi.org/10.1080/20964129.2018.1530054

[35] Arora, N.K. (2019). Impact of climate change on agriculture production and its sustainable solutions. Environmental Sustainability, 2(2): 95-96. https://doi.org/10.1007/s42398-019-00078-w 